\title{
Article \\ Influence of Polyvinyl Alcohol Powder on the Mechanical Performance and Volume Stability of Sulfoaluminate-Portland Cement Composite
}

\author{
Yuhong He *, Liwu Mo, Zhongyang Mao, Fufan Huang and Zhenghao Han \\ College of Materials Science and Engineering, Nanjing Tech University, Nanjing 211800, China; \\ andymoliwu@njtech.edu.cn (L.M.); mzy@njtech.edu.cn (Z.M.); 201821003244@njtech.edu.cn (F.H.); \\ 201821003243@njtech.edu.cn (Z.H.) \\ * Correspondence: 201861203088@njtech.edu.cn; Tel.: +86-15720601184
}

Citation: He, Y.; Mo, L.; Mao, Z.; Huang, F.; Han, Z. Influence of Polyvinyl Alcohol Powder on the Mechanical Performance and Volume Stability of Sulfoaluminate-Portland Cement Composite. Crystals 2021, 11, 692. https://doi.org/10.3390/ cryst11060692

Academic Editor: Tomasz Sadowski

Received: 8 May 2021

Accepted: 10 June 2021

Published: 17 June 2021

Publisher's Note: MDPI stays neutral with regard to jurisdictional claims in published maps and institutional affiliations.

Copyright: (c) 2021 by the authors. Licensee MDPI, Basel, Switzerland. This article is an open access article distributed under the terms and conditions of the Creative Commons Attribution (CC BY) license (https:// creativecommons.org/licenses/by/ $4.0 /)$

\begin{abstract}
Cement quick repair materials generally have the defects of brittleness and early shrinkage. The modification of composite cement mortar by water-soluble glue powder-polyvinyl alcohol (PVA) - was studied in the condition of settled water cement ratio. At 90 days, the maximum flexural strength of mortar was $15.4 \mathrm{MPa}$, which was 1.3 times of the group without PVA and there was no strength shrinkage phenomenon. Through the analysis of the porosity, PVA improved the total porosity; high porosity could play a better role of buffering and absorbing the impact stress, effectively improving the toughness of mortar. At 28 days, the maximum impact resistance was $1.72 \mathrm{~J} / \mathrm{cm}^{2}$, which was 1.75 times of the group without PVA. In addition, the increased total porosity also greatly absorbed the shrinkage stress at the early stage, and reduced the mortar self-shrinkage. When the PVA content was $1 \%$, the volume self-shrinkage of mortar decreased from the initial $3360 \mu \mathrm{m} \cdot \mathrm{m}^{-1}$ to $700 \mu \mathrm{m} \cdot \mathrm{m}^{-1}$. According to the analysis of hydration heat, the addition of PVA effectively reduced the early hydration heat release rate and alleviated the concentrated heat release phenomenon to a certain extent. In this paper, the hydration reaction of composite cement and the action mechanism of PVA in composite cement were studied by means of X-ray diffraction, infrared spectrum and hydration heat analysis.
\end{abstract}

Keywords: cement repair material; polymer; early strength; toughness; autogenous shrinkage

\section{Introduction}

Concrete is the most widely used construction material in the world. Compared with other kinds of repair materials, cement-based repair materials have a great advantage in cost. In addition, high strength and durability are also important reasons for the wide application of cement-based repair materials, but the lack of toughness is also a major defect of cement-based materials. Although the durability of cement concrete was better, during the long-term service the cement concrete material was inevitably appearing aged, damaged and had other issues. The cost of rebuilding, especially under the condition of damage was not serious, but if a deaf ear to damage location was likely to develop into more serious damage, this would affect the normal use of concrete material [1]. Therefore, it was necessary to repair the damaged cement concrete in time.

Conventional Portland cement was widely used to repair the concrete structures. As a result of the relatively slow hydration process, the repaired concrete structures, such as bridges, pavements, etc., needed to wait for a long period of 14 days or even 28 days to reopen. This is not acceptable for some urgent situations. Therefore, rapid setting and rapid strength development are important properties for the repair materials. If conventional Portland cement was used for repair, the hydration was slow, the maintenance time was 5-7 days, the early strength was low, the requirements for construction equipment and maintenance after repair were high, and the time consuming and laborious effect 
was poor [2]. There were many kinds of concrete repair material, such as magnesium phosphate cement [3,4], rapid hardening Portland cement [5], etc., including sulfoaluminate cement, which was the special cement with independent intellectual property rights in our country, although it was not a mainstream product for the construction industry, but the sulfoaluminate cement sintering temperature was lower than Portland cement and the amount of carbon dioxide emissions was less; if sulfoaluminate cement could partly replace Portland cement, it would have a very good benefit in energy conservation and emissions reduction [6-8].

Previous studies have shown that the combination of Portland cement and sulfoaluminate cement would lead to some synergetic effects, in terms of rapider setting, higher strength at an early age, etc., owing to the enhanced hydration of both cements [9-11]. However, the composite cement, which, mixed with Portland cement and sulfoaluminate cement, also had the inherent defects of cement materials, such as high brittleness, insufficient toughness and poor flexural performance. At the same time, the cement rapid repairing materials hydration heat concentrated at an early age, which led to bigger early shrinkage when the contract was a certain constraint function, which would produce certain shrinkage stress within the mending material; the greater the value, the greater the contraction force. When the shrinkage stress exceeds the tensile strength of the repaired material itself, the mortar could produce cracks, especially in the connection part of the old matrix and the repair material, which leads to the failure of repair [12,13]. Adding polymer into mortar or concrete could be used as a method to solve the lack of toughness and reduce the volume shrinkage of cement mortar. In recent years, many scholars have studied polymer coagulation [14-16]. Nowadays, various types of polymers were used by scholars in the study of mortar or concrete. Vahab Toufigh found that the addition of epoxy resin into PC concrete greatly improved the elastic modulus of the concrete. E.Knapen found that a little amount of water-soluble polymer polyethylene-acetate (PVAA) was added into PC mortar. It was observed that PVAA had a good film-forming property, wrapped a part of the hydration products and played a "bridge" role between the hydration products [17-21]. There are many kinds of polymers, and the modification mechanism of different polymers was different. At present, the research of polymers in cement rapid repair materials is rare.

The effect of polymers on the cement hydration process and structure formation was complex, and Ohama's polymer network model and Konietzko's double network model were the most accepted and classic models. The polymers were uniformly dispersed in the composite cement. As the free water in the hydration of the composite cement decreased, the polymers kept accumulating together and eventually fused together to form a continuous mesh polymer film. At the same time, the cement also formed a continuous mesh structure in the polymer network. Finally, the polymer film and cementing materials interweaved together to form a three-dimensional interlocking network structure, which improved defects such as high brittleness, large shrinkage deformation and poor corrosion resistance, and optimized the working performance of the cement mortar, making the modified repair cement-based materials develop into flexible materials [22-25]. As a watersoluble polymer PVA can be dispersed in the cement slurry better, by the same way PVA was used as a kind of adhesive, too. Adding it into the cement slurry can effectively improve the bonding performance of cement. In this study, the effect of polymer polyvinyl alcohol powder (PVA) on PC-SAC composite cement mortar (composite cement) was evaluated by using mechanical property results, early self-shrinkable, thermo-gravimetric analysis (TG), heat of hydration analysis, pore structure analysis, scanning electron microscopy (SEM), and infrared spectroscopy (IR).

\section{Materials}

\subsection{Cement Materials}

\subsubsection{Raw Material and Mix Ratio}

Portland cement (PC.II52.5) was produced in Jiang nan xiao ye tian company, sulfoaluminate cement (R.42.5) was produced in Yi cheng Anda special cement company (SAC), 
polyvinyl alcohol powder (PVA) was produced in Anhui WanWei huashan new materials company. Chemical composition and mineral composition of PC and SAC were tested by XRF and XRD as shown in Table 1 and Figure 1. It was observed that the main minerals of PC were alite $\left(C_{3} S\right)$, belite $\left(C_{2} S\right)$, and calcite, and SAC were Ye'elimite and gypsum.

Table 1. Chemical composition of SAC and PC.

\begin{tabular}{ccccccccccc}
\hline Code & $\mathrm{CaO}$ & $\mathrm{Al}_{\mathbf{2}} \mathbf{O}_{\mathbf{3}}$ & $\mathrm{SO}_{\mathbf{3}}$ & $\mathrm{SiO}_{\mathbf{2}}$ & $\mathrm{Fe}_{\mathbf{2}} \mathbf{O}_{\mathbf{3}}$ & $\mathbf{M g O}$ & $\mathrm{Na}_{\mathbf{2}} \mathbf{O}$ & $\mathbf{K}_{\mathbf{2}} \mathbf{O}$ & $\mathrm{LOI}$ & Total \\
\hline $\mathrm{SAC}$ & 41.12 & 20.65 & 14.02 & 9.59 & 6.79 & 1.84 & 0.20 & 0.13 & 4.02 & 98.36 \\
$\mathrm{PC}$ & 64.06 & 5.07 & 1.88 & 19.92 & 2.87 & 1.22 & 0.35 & 0.23 & 4.4 & 100 \\
\hline
\end{tabular}

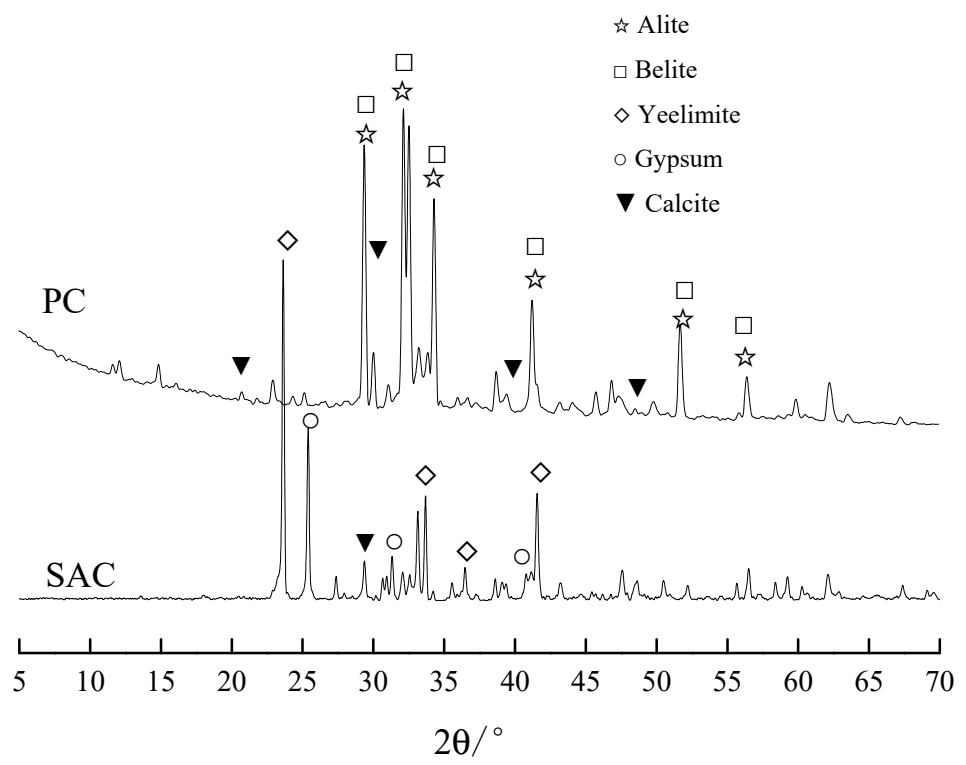

Figure 1. XRD patterns of PC and SAC.

\subsubsection{Preparation of Specimens}

The composite cement contained PC and SAC, as shown in Table 2, SAC was replaced by $30 \%$ of PC; water-to-cement ratio $(\mathrm{w} / \mathrm{c}$ ) was chosen as 0.23 (ensure the mortar to achieve self-leveling), cement-to-sand ratio was $1 / 1$ (the standard sand consistent with ISO 679); content of PVA was 0-2\% of cement. Preparation of mortars was in accordance with Chinese standard GB/T 175-2007, mortars were casted into molds and cured in the standard $20 \pm 1^{\circ} \mathrm{C}$. After demolded, mortars were cured in air condition and temperature was $20 \pm 1^{\circ} \mathrm{C}$, relative humidity was $50 \%$.

Table 2. Mix proportions of composite cement.

\begin{tabular}{cccccc}
\hline Code & SAC & PC & Anhydrite & Water & PVA \\
\hline D0 & 65 & 30 & 5 & 230 & 0 \\
P0.5 & 65 & 30 & 5 & 230 & 0.5 \\
P1 & 65 & 30 & 5 & 230 & 1 \\
P1.5 & 65 & 30 & 5 & 230 & 1.5 \\
P2 & 65 & 30 & 5 & 230 & 2 \\
\hline
\end{tabular}

Preparation and curing of pastes were the same as mortars. At the specific curing age, pastes were crushed into small pieces and then were immersed into ethanol to stop hydration. After being dried in a vacuum at $50{ }^{\circ} \mathrm{C}$ for 3 days, small pieces of pastes were used for the test of SEM and MIP. Furthermore, small pieces were also grinded to pass through $80 \mu \mathrm{m}$ sieve for the test of hydrates, such as XRD and TG. 


\subsection{Methods}

\subsubsection{Strength}

According to the strength test of GB/T 17671, mortars with the dimension of $40 \times 40 \times 160 \mathrm{~mm}^{3}$ were used for the measurement of compressive strength at the age of $4 \mathrm{~h}, 1$ day, 28 days, 90 days. Compressive strength and flexural strength was tested by compressive machine (AEC-201), the displacement speed was set up to $(2400 \pm 200) \mathrm{N} / \mathrm{S}$ and $(50 \pm 10) \mathrm{N} / \mathrm{S}$.

\subsubsection{Volumetric Stability}

A German Micro-Epsilon displacement sensor was used to measure the early volumetric shrinkage (or expansion) of mortar. Thread pipe length was $42 \mathrm{~cm}$, outer diameter was $28 \mathrm{~mm}$, and inner diameter was $20 \mathrm{~mm}$. The mortar was added into the threaded pipe and fully vibrated to avoid the pipe cavity, the threaded pipe was sealed and placed in the inner diameter of $60 \mathrm{~mm}$ pipe, solidifying one end to ensure the linear contraction (expansion) of the threaded pipe. During the test, it was strictly forbidden to touch the threaded pipe and laser equipment, and the ambient temperature should be controlled at $20 \pm 1{ }^{\circ} \mathrm{C}$.

The calculation of mortar volume deformation is shown in Equation (1).

$$
\omega=\Delta l / L
$$

where $\Delta l$ is the shrinkage of threaded tube $(\mu \mathrm{m}), L$ is the length of threaded pipe $(\mathrm{m}), \omega$ is the shrinkage of mortar in microns per meter $(\mu \mathrm{m} / \mathrm{m})$.

\subsubsection{Impact Resistance}

Impact resistance was a way to evaluate the toughness of materials. Mortars with the dimension of $300 \times 300 \times 20 \mathrm{~mm}^{3}$ were used for the measurement of impact resistance at the age of 1 day and 28 days.

According to the Chinese standard the impact resistance test method for ceramics was used to test the impact resistance of mortar (GB/T 38494-2020). When the iron ball falls on the surface of mortar and produces visible cracks with the origin of the drop point, the impact resistance energy was regarded as the initial impact resistance energy of mortar. The greater the impact resistance, the better the toughness of mortar. The second impact of the falling ball on mortar must be avoided in the test process.

The calculation of impact strength is shown in Equations (2) and (3).

$$
\begin{aligned}
& S=I / t^{2} \\
& I=m g H
\end{aligned}
$$

where $S$ is the impact strength of mortar $\left(\mathrm{J} / \mathrm{cm}^{2}\right), I$ is the impact energy $(\mathrm{J}), t$ is the thickness at the point of impact $(\mathrm{cm}), m$ is the quality of the iron ball $(\mathrm{kg}), g$ is the gravity $\left(\mathrm{m} / \mathrm{s}^{2}\right), H$ is the distance between iron ball and mortar plate $(\mathrm{m})$.

\subsubsection{Hydration Heat}

Hydration heat of pastes was tested by an isothermal calorimeter at $20^{\circ} \mathrm{C}$. The proportion of pastes was the same as in Table 2 . The data were automatically recorded by the apparatus for 3 days.

\subsubsection{Hydrates Assemblages}

(1) X-ray diffraction (XRD):

The phase composition of the hydration products was analyzed by $\mathrm{X}$-ray diffractometer. The speed was $10^{\circ} / \mathrm{min}$, and the scanning range was $5 \sim 80^{\circ}$. The equipment was manufactured by Rigaku company of Japan with a power of $3 \mathrm{kw}$. 
(2) Thermogravimetric (TG):

The hydration products were analyzed with a comprehensive thermal analyzer. In nitrogen atmosphere, the temperature rose from room temperature to $900{ }^{\circ} \mathrm{C}$ at a heating rate of $20^{\circ} \mathrm{C} / \mathrm{min}$. The equipment was manufactured by Netzsch company of Germany and the model is STA449C.

\subsubsection{Microstructure Characterization}

(1) Mercury intrusion porosimetry (MIP):

The pore structures of the hydration samples at $4 \mathrm{~h}$ and 28 days were measured by mercury injection apparatus. The equipment was manufactured by Quantachrome company of America and the model is PoreMaster 2005.

(2) Surface fractal characteristics:

Emission scanning electron microscopy (SEM) was used to observe the microstructure of the samples at hydration ages of $4 \mathrm{~h}$ and 28 days. The equipment was manufactured by JEOL company of Japan and the model is S-5900.

(3) Infrared analysis:

Fourier transforms infrared spectra (FTIR) of powder samples PVA, unhydrated D0, D0, unhydrated P2, and P2 were recorded by an FTIR spectrometer (Nicolet IS 10 IR). To realize the FTIR, $0.1 \mathrm{mg}$ paste powder was mixed with $100 \mathrm{mg} \mathrm{KBr}$ to make slices.

\section{Results and Discussion}

\subsection{Flexural and Compressive Properties and Flexural Compressive Ratio}

The flexural strength and compressive strength of composite cement were tested to 90 days, and the results are shown in Figure 2a,b. The flexural strength of mortar at each age was gradually increased with the increase in PVA powder content. At $4 \mathrm{~h}$, compared with D0, the flexural strength of P2 was increased from $8.06 \mathrm{MPa}$ to $10.41 \mathrm{MPa}$, an increase of $29.1 \%$. At 28 days, the flexural strength of P2 was increased from $10.79 \mathrm{MPa}$ to $14.02 \mathrm{MPa}$, compared with $\mathrm{D} 0$, an increase of $29.9 \%$. At 90 days, the flexural strength of $\mathrm{P} 2$ was increased from $11.69 \mathrm{MPa}$ to $15.4 \mathrm{MPa}$, compared with D0, an increase of $31.7 \%$. However, the change in the compressive strength of mortar was just opposite the change in the flexural strength, which was the same as the research results of many scholars. The compressive strength decreases with the increase in the gathering ratio [26-28], because the strength of the polymer was less than the strength of the cement [29]. At $4 \mathrm{~h}$, the compressive strength of $\mathrm{P} 2$ was decreased from $56.99 \mathrm{MPa}$ to $45.56 \mathrm{MPa}$, compared with D0, which decreased by $20.1 \%$. At 28 days, the compressive strength of P2 was decreased from $90.86 \mathrm{MPa}$ to $83.59 \mathrm{MPa}$, compared with D0, which decreased by $8 \%$. At 90 days, the compressive strength of $\mathrm{P} 2$ was decreased from $108.25 \mathrm{MPa}$ to $92.72 \mathrm{MPa}$, compared with the group D0, which decreased by $14.3 \%$. The flexural strength was increased with the increase in the PVA content, and the compressive strength with the increase in the PVA content was lower, which made the flexural compression ratio of mortar increase with the PVA content, as shown in Figure 3. The higher the PVA content, the greater the mortar flexural compression ratio; the greater the mortar flexural compression ratio could reflect the change in the mortar toughness, and the greater the flexural compression ratio of mortar, the better the toughness $[29,30]$. This was enough to regard that PVA powder could effectively improve the toughness of composite cement. 


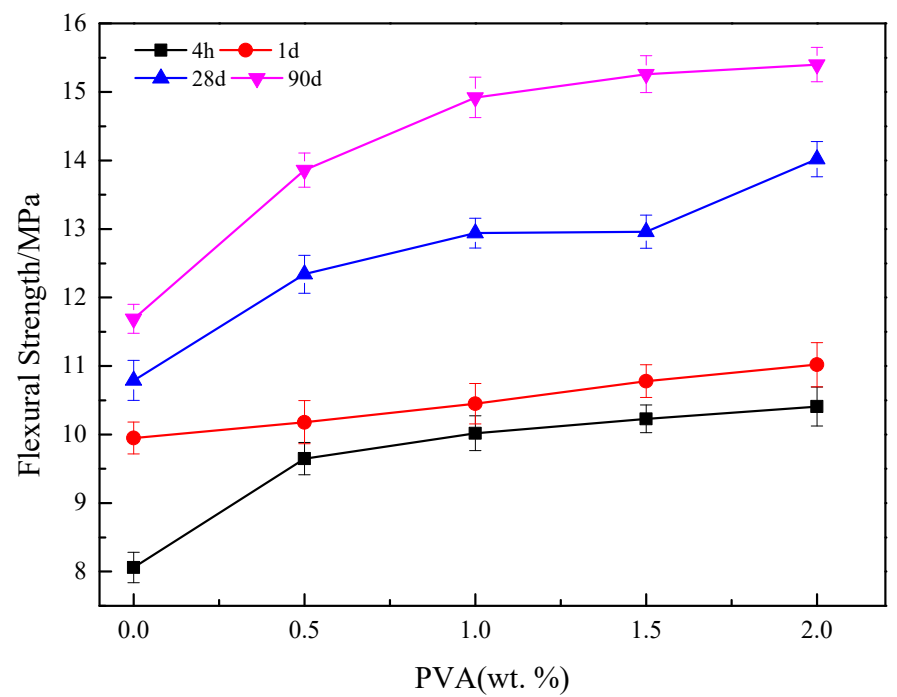

(a)

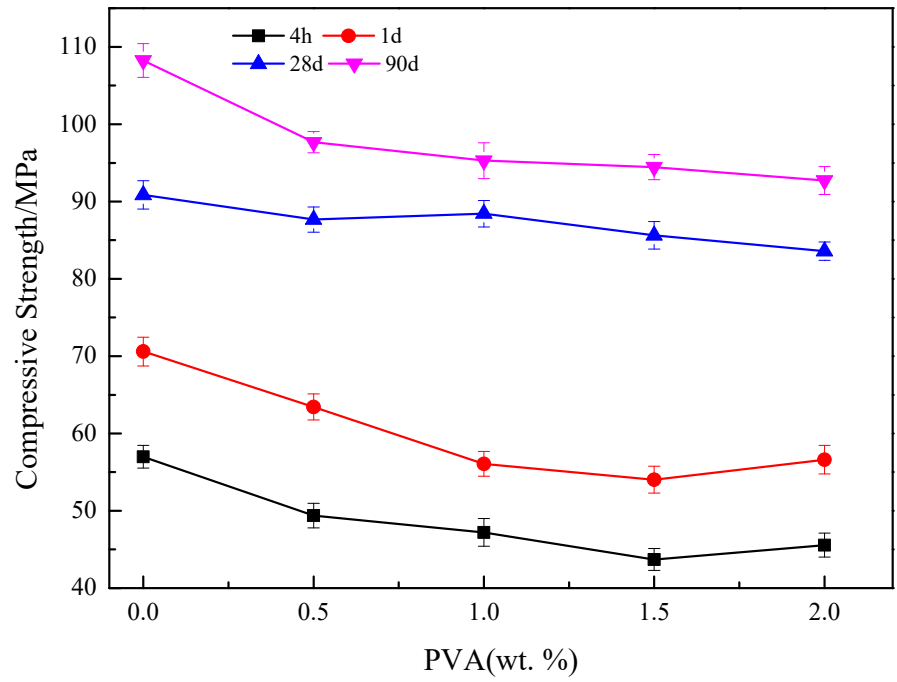

(b)

Figure 2. Mechanical properties of mortar. (a) The flexural strength of mortar; (b) the compressive strength of mortar.

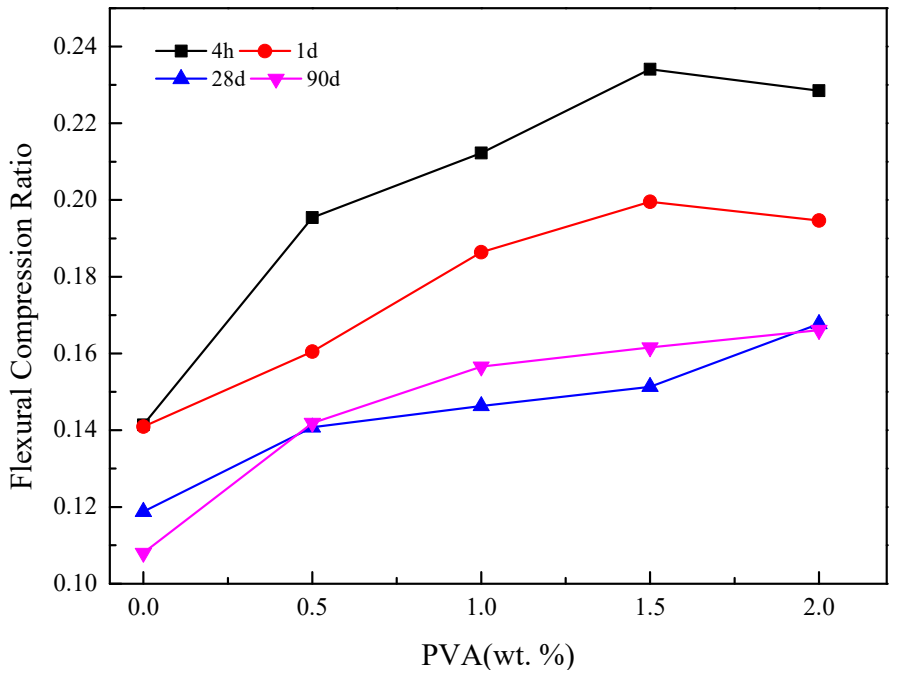

Figure 3. The flexural compression ratio of mortar. 


\subsection{Volume Deformation and Fluidity}

Because of the rapid hydration rate of cement quick repair material, resulting in large early shrinkage, this study was aimed at testing the early autogenous shrinkage of composite cement. Before the mortar reached the initial setting state, the fluidity was large and the plasticity was strong. Therefore, the volume deformation before the initial setting belonged to the plastic deformation and would not cause the cracking of mortar.

Shown in Figure 4, when the mortar reached the initial setting we began counting. The main component of composite cement was SAC, and its hydration product AFt had an expansion effect, besides the rapid hydration of composite cement, which produced a large amount of hydration heat. So, before the emergence of a large expansion process there was a quick shrinkage. The expansion part contains both the thermal expansion of mortar and hydration products, the expansion of the threaded pipe cooling to room temperature in the process, the hydration heat of thermal expansion gradually disappearing, and, finally, the only expansion effect was the hydration of composite cement. Therefore, all of the curves in Figure 4 show, first, the contraction, then expansion, then contraction, and finally stability. As shown in Figure 4, the addition of PVA effectively improved the expansion value of the composite cement. With the addition of PVA increasing from 0 to $2 \%$, the shrinkage values of mortar were $3360 \mu \mathrm{m} \cdot \mathrm{m}^{-1}, 2800 \mu \mathrm{m} \cdot \mathrm{m}^{-1}, 700 \mu \mathrm{m} \cdot \mathrm{m}^{-1}, 1020 \mu \mathrm{m} \cdot \mathrm{m}^{-1}$, and $1170 \mu \mathrm{m} \cdot \mathrm{m}^{-1}$. It implied that the addition of PVA could effectively reduce the self-shrinkage of mortar, and the self-shrinkage value was the minimum when the content of PVA was $1 \%$.

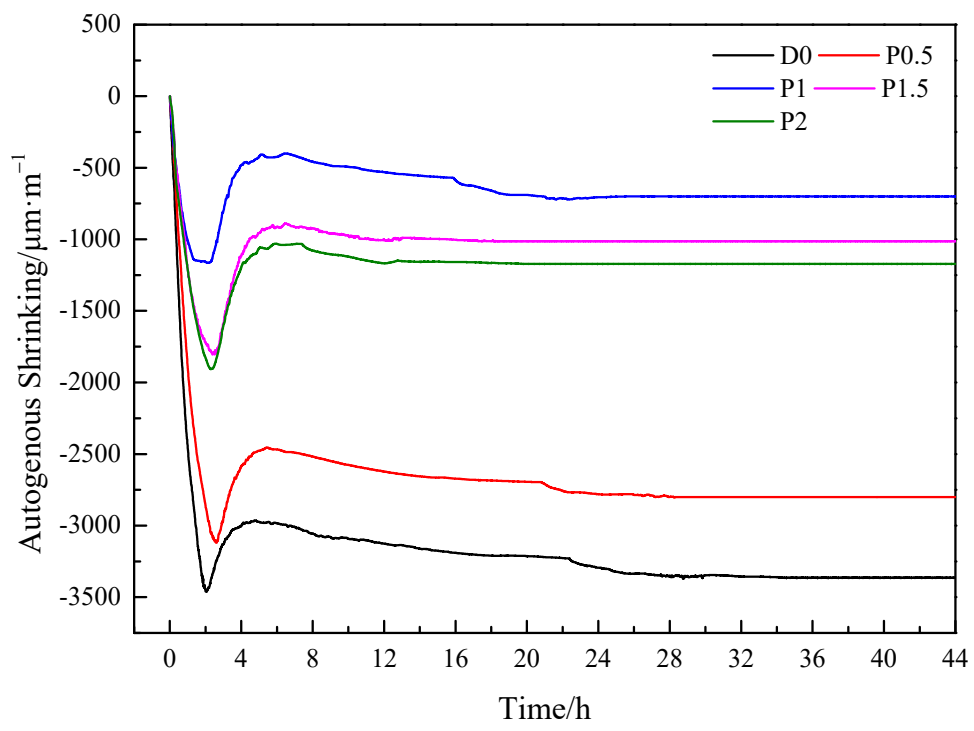

Figure 4. The autogenous shrinkage of mortar.

\subsection{Impact Resistance}

There were the following three ways to evaluate the toughness of materials: lateral deformation, flexural compression ratio, and impact resistance. Lateral deformation was applicable to materials with high toughness, flexural compression ratio was applicable to materials with high brittleness, and impact resistance was applicable to both high toughness materials and brittleness materials [31].

The initial impact resistance of composite cement at 1 day and 28 days was studied, as shown in Figure 5. The addition of PVA could greatly improve the impact resistance of mortar. At 1 day, the impact resistances of the D0 and experimental groups were $0.49 \mathrm{~J} / \mathrm{cm}^{2}$, $1.10 \mathrm{~J} / \mathrm{cm}^{2}, 0.98 \mathrm{~J} / \mathrm{cm}^{2}, 1.35 \mathrm{~J} / \mathrm{cm}^{2}, 1.23 \mathrm{~J} / \mathrm{cm}^{2}$, respectively, and the impact resistances of each of the experimental groups were $200 \%, 224 \%, 251 \%$ and $276 \%$, respectively, of that in D0. The addition of PVA could effectively improve the toughness of the mortar, and it worked at the early age. When curing to 28 days, the impact resistance of each group increased with the increase in mortar strength, and the impact resistance of P2 was 
increased by $75.5 \%$, compared with that of D0. The law of the impact resistance curve of mortar corresponded to the flexural compression ratio of the corresponding age. PVA had good toughness and good solubility in water; after mixing with cement materials, it could form the three dimensional space structure, which cement and PVA package of each other $[14,24,25]$.

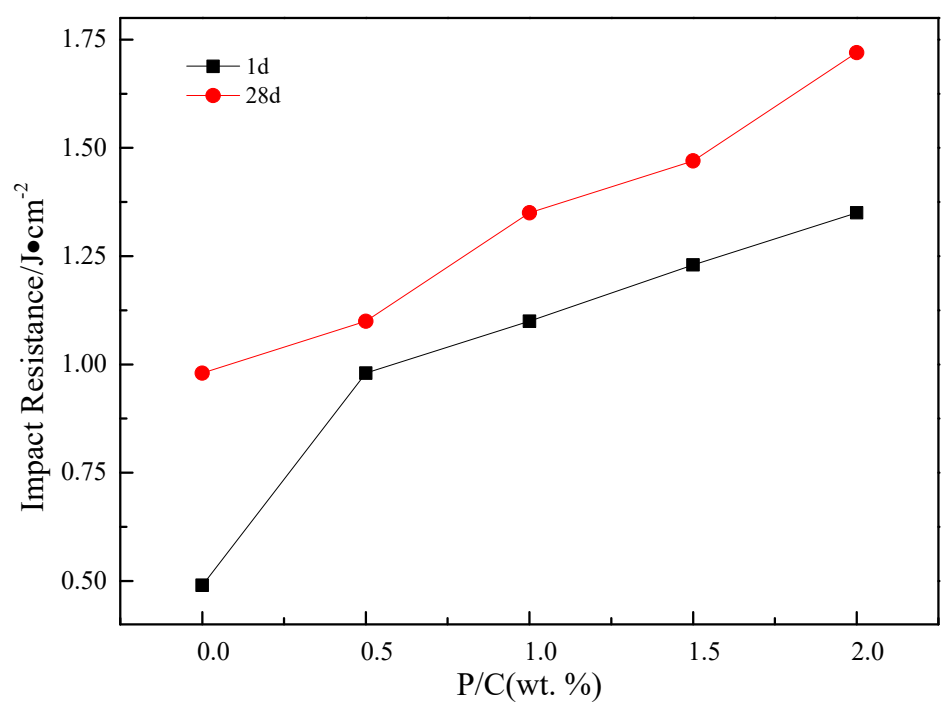

Figure 5. The impact resistance of mortar.

Some polymer powder contains a carboxyl group, which is a kind of highly active functional group. It could chelate with $\mathrm{Ca}^{2+}$ to generate calcium carboxylate; cement and chelate were connected by chemical bonds so as to improve the toughness of cement [32-34]. The essence of the chelation reaction was an acid-based neutralization reaction. The hydroxyl group in PVA also has certain reactivity. However, if PVA reacted with $\mathrm{Ca}(\mathrm{OH})_{2}$ to form alcohol calcium, the basic chemical principle of strong base to weak base would be violated. Therefore, PVA would not react in composite cement. From Figure 6, the difference in the infrared absorption peaks between unhydrated D0 and D0 was $2800-4800 \mathrm{~cm}^{-1}$, which was the absorption peak of $-\mathrm{OH}$, while the main product of D0 was AFt, which contains bound water. The infrared absorption peaks of PVA, unhydrated $\mathrm{P} 2$, and P2 were also different in the range of 2800 to $4800 \mathrm{~cm}^{-1}$. It could be concluded, from the above results, that PVA improved the toughness of mortar only by physical action.

\subsection{Hydration Heat of Composite Cement}

The early hydration process of composite cement could be explained by the determination of hydration heat. The main body of composite cement in this study was SAC, so the hydration process of the composite cement was dominated by SAC [10]. Firstly, SAC had the hydration reaction to produce ettringite and hydrated alumina hydroxide, while giving of a large amount of heat. On the one hand, the increase in temperature promotes the hydration of more anhydrous calcium sulphoaluminate, and $C_{3} A$ and $C_{3} S$; on the other hand, the ettringite generated first also acted as a nucleating seed to further promote the hydration of cement particles [35,36]. Then, the hydration product $\mathrm{CH}$ of $\mathrm{C}_{3} \mathrm{~S}$ reacted with hydrated alumina hydroxide in the case of excess gypsum to further generate ettringite [9,37], and finally formed a mutually filled structure with ettringite as skeleton and CSH and cement particles. 


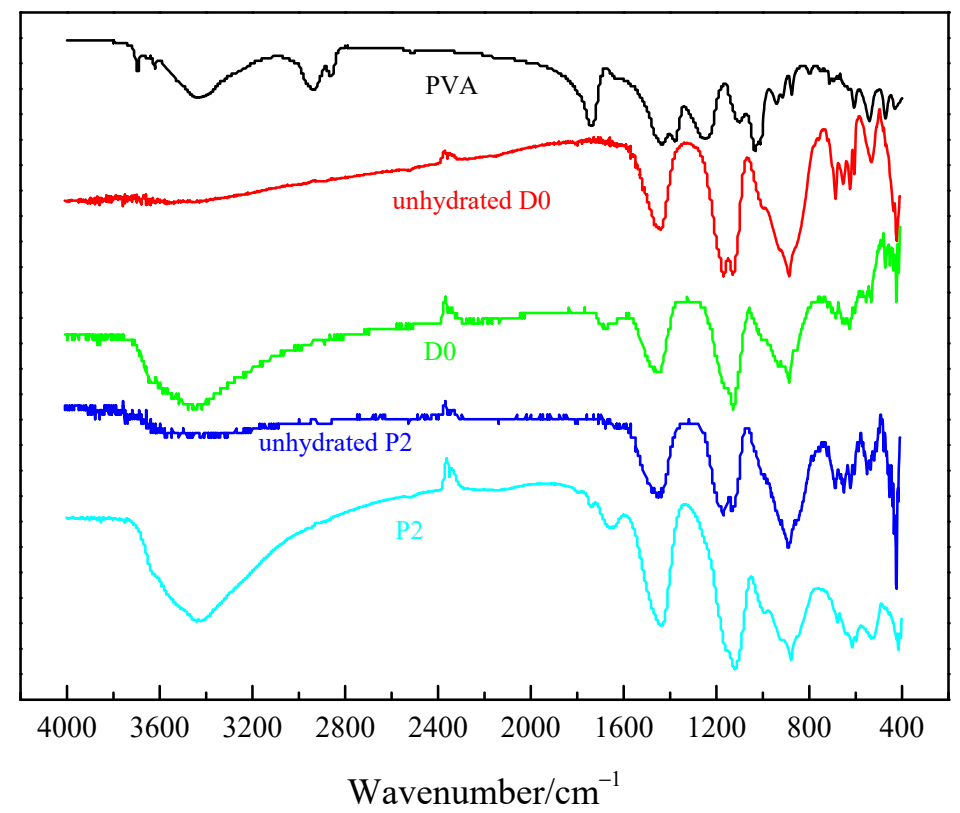

Figure 6. The infrared analysis diagram of material and cement.

The hydration heat release rate and total heat release of composite cement are shown in Figures 7 and 8. As shown in Figure 7, the heat release of hydration was mainly concentrated in the early stage, the heat release rate was closed to 0 after $5 \mathrm{~h}$, and there was no heat release peak. Composite cement early hydration was mainly composed of two exothermic peaks. The first exothermic peak was explained by cement particles and exothermic water solubility, and there was nearly no difference between the experimental groups and the D0 group, all of them were finished in a very short time. The second heat peak was sharp, mainly explained by the hydration of the $\mathrm{C}_{3} \mathrm{~S}$ and calcium sulfoaluminate cement, and the hydration rate of the D0 group was far greater than the other experimental groups, which was due to the PVA that encapsulated the cement particles to delay the hydration of the cement $[24,25]$. As shown in Figure 8, due to the retarding effect of PVA, the total amount of heat in the D0 group before $3.2 \mathrm{~h}$ was slightly greater than that in the experimental group, while the total amount of heat in all components in $1 \mathrm{~d}$ would be flat, indicating that the PVA would not have too much adverse effect on the amount of heat release.

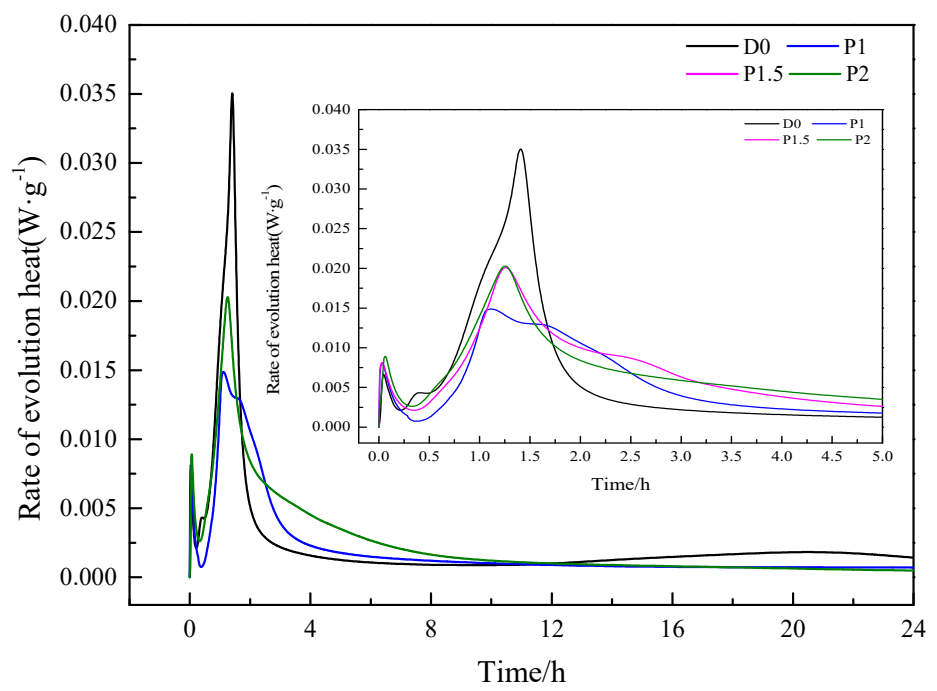

Figure 7. The rate of evolution heat of composite cement. 


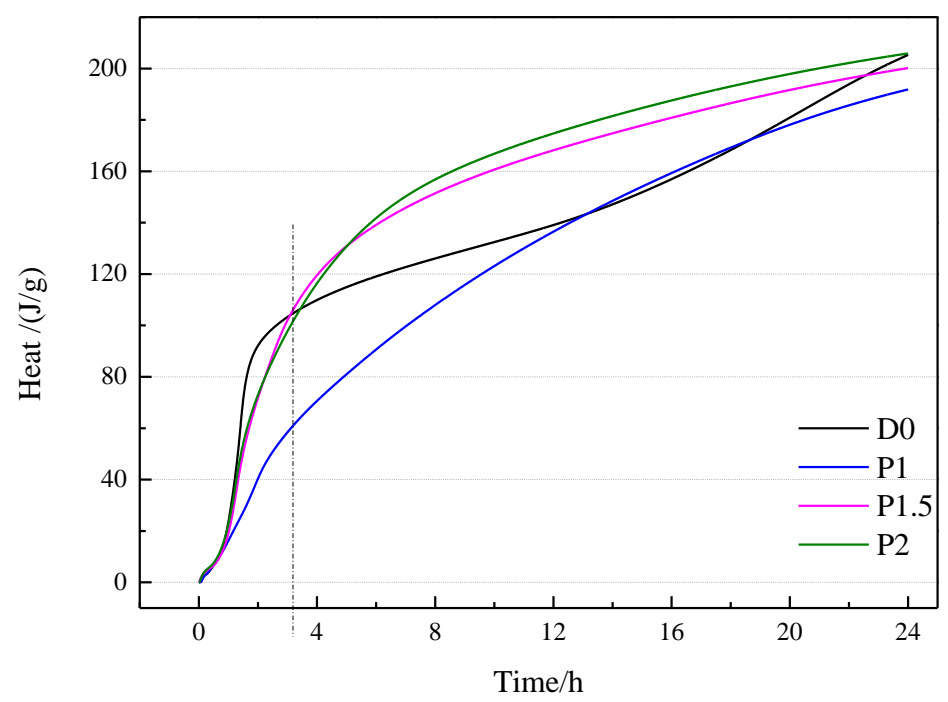

Figure 8. The hydration heat of composite cement.

\subsection{Hydrates Analysis}

(1) XRD analysis:

XRD was an effective method to analyze hydration products. Figure 9 shows an XRD diagram of composite cement at $4 \mathrm{~h}$, the detected substances were ettringite and Ye'elimite, gypsum, and calcium silicate, which have not yet been hydrated. At 28 days, there was still existing gypsum, in Figure 10, which indicated that gypsum was excessive. Therefore, it could be considered that the hydration products of the composite cement were basically $\mathrm{AFt}$, which provided strength for the mortar. In the case of excess gypsum, the hydration reaction of composite cement was shown as Equations (4)-(6) $[9,37]$.

$$
\begin{gathered}
3 \mathrm{CaO} \cdot 3 \mathrm{Al}_{2} \mathrm{O}_{3} \cdot \mathrm{CaSO}_{4}+\mathrm{H}_{2} \mathrm{O}+\mathrm{CaSO}_{4} \rightarrow 3 \mathrm{CaO} \cdot \mathrm{Al}_{2} \mathrm{O}_{3} \cdot 3 \mathrm{CaSO}_{4} \cdot 32 \mathrm{H}_{2} \mathrm{O}+\mathrm{Al}(\mathrm{OH})_{3}(\mathrm{gel}) \\
3 \mathrm{CaO} \cdot \mathrm{SiO}_{2}+\mathrm{H}_{2} \mathrm{O} \rightarrow \mathrm{CaO}-\mathrm{SiO}_{2}-\mathrm{H}_{2} \mathrm{O}(\mathrm{gel})+\mathrm{Ca}(\mathrm{OH})_{2} \\
\mathrm{Al}(\mathrm{OH})_{3}+\mathrm{Ca}(\mathrm{OH})_{2}+\mathrm{CaSO}_{4}+\mathrm{H}_{2} \mathrm{O} \rightarrow 3 \mathrm{CaO} \cdot \mathrm{Al}_{2} \mathrm{O}_{3} \cdot 3 \mathrm{CaSO}_{4} \cdot 32 \mathrm{H}_{2} \mathrm{O}
\end{gathered}
$$

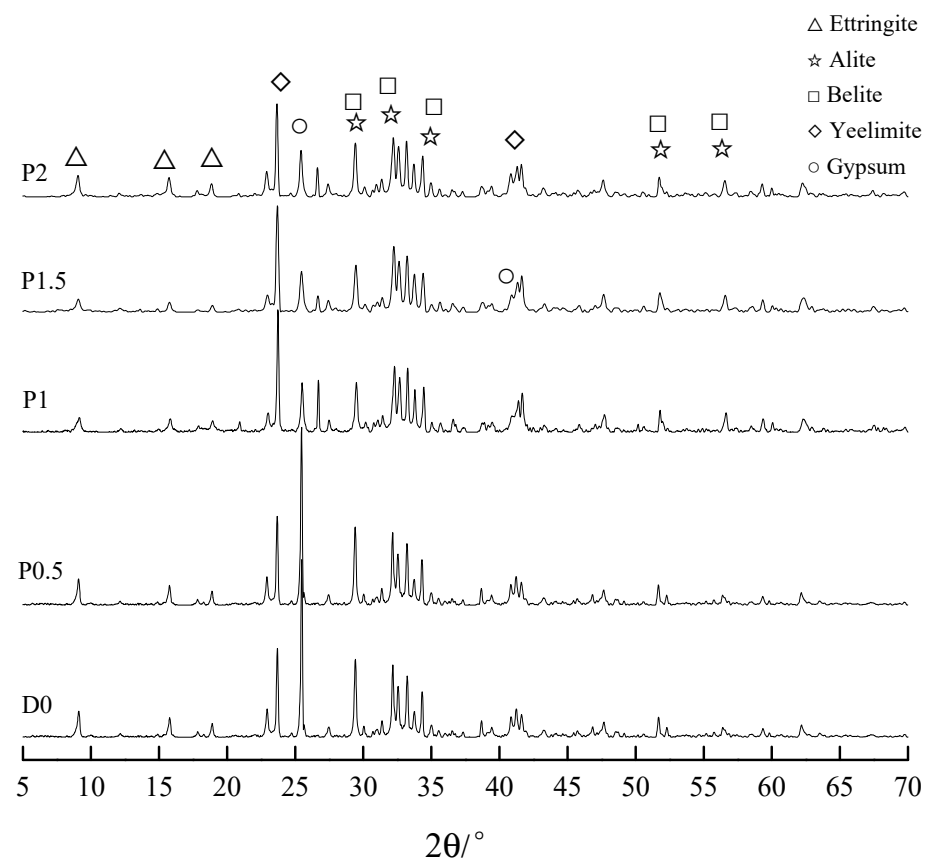

Figure 9. XRD patterns of composite cement at $4 \mathrm{~h}$. 

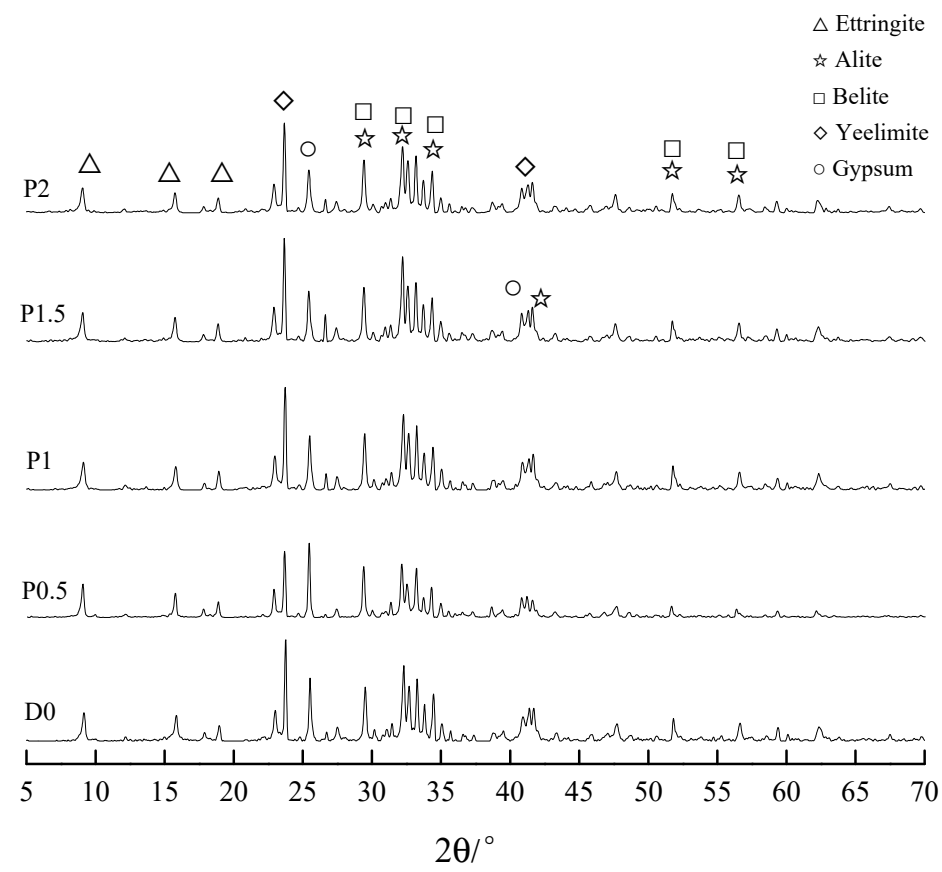

Figure 10. XRD patterns of composite cement at $28 \mathrm{~d}$.

Firstly, Ye'elimite started to hydrate to form AFt and aluminum glue, and then calcium silicate reacted with hydration to form $\mathrm{CSH}$ gel and calcium hydroxide. Because gypsum was excessive, calcium hydroxide, gypsum and aluminum glue reacted to generate more AFt. From Figures 9 and 10, these were not the diffraction peaks of calcium hydroxide, indicating the secondary reaction of all calcium hydroxide generated by hydration. By the way, the AFt generated first became the skeleton attached to the CSH gel, and the two cement particles and their hydration products filled each other, making the mortar denser and obtain a higher strength $[9,37]$.

(2) TG-DSC analysis:

TG-DSC was used to analyze the decomposition process of hydration products. According to Figure 11, these had two obvious endothermic peaks, which belong to the hydration products of D0, P1 and P2. From $80{ }^{\circ} \mathrm{C}$ to $160^{\circ} \mathrm{C}$ was the endothermic peak of AFt losing bound water. The endothermic peak of $250{ }^{\circ} \mathrm{C}$ was mainly $\mathrm{Al}(\mathrm{OH})_{3}$ (gel) decomposition. The endothermic peak of $700^{\circ} \mathrm{C}$ was mainly caused by the decomposition of calcium carbonate, and around the temperature of $400{ }^{\circ} \mathrm{C}$ there were no apparent endothermic peaks; combined with Figure 9, it could be inferred that there was no calcium hydroxide in the hydration products. According to Figures 11 and 12, the total amount of ettringite generated by each component at different ages could be calculated [38], as shown in Table 3. It could be inferred that PVA had no effect on the production of AFt.

Table 3. Amount of ettringite (wt. \%).

\begin{tabular}{|c|c|c|}
\hline Age & Sample & Total AFt $/ \%$ \\
\hline \multirow{3}{*}{$4 \mathrm{~h}$} & D0 & 17.02 \\
\hline & P1 & 16.15 \\
\hline & $\mathrm{P} 2$ & 15.48 \\
\hline \multirow{3}{*}{$28 \mathrm{~d}$} & D0 & 20.31 \\
\hline & P1 & 18.11 \\
\hline & P2 & 20.57 \\
\hline
\end{tabular}




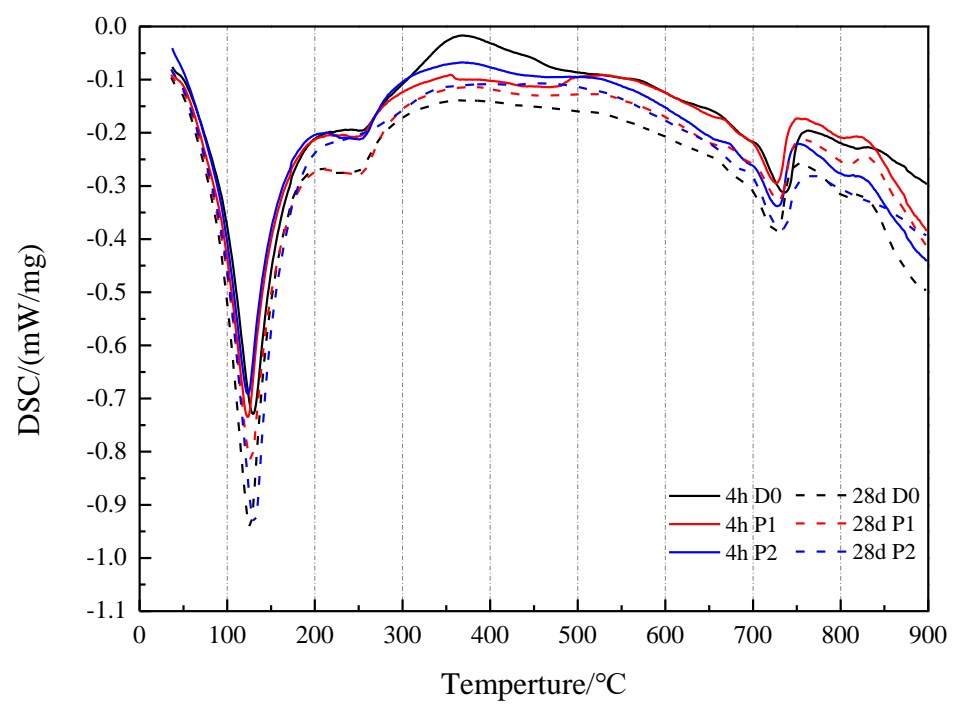

Figure 11. DSC curves of composite cement in $\mathrm{N}_{2}$ atmosphere.

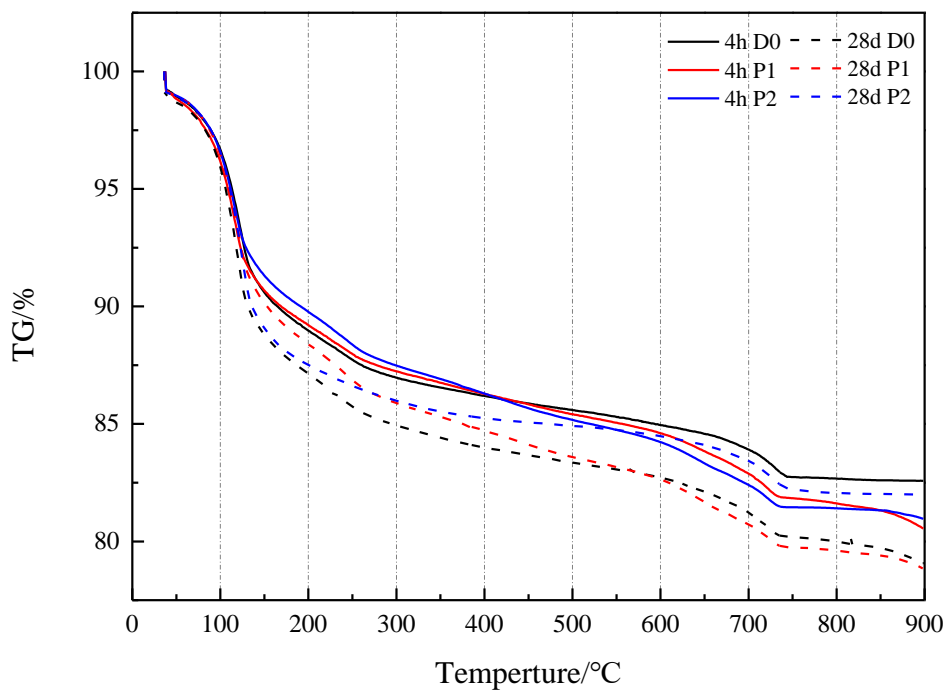

Figure 12. TG curves of composite cement in $\mathrm{N}_{2}$ atmosphere.

(3) MIP analysis:

Porosity and the distribution of pore size was an effective method to characterize the evolution of the microstructure. Figure 13a,b, are pore distributions of each sample at $4 \mathrm{~h}$ and 28 days. The total porosity of the sample was P2 $>$ P1 $>$ D0, because the PVA had the effect on air intake. The greater the amount of mixing, the greater the amount of air intake. A pore size larger than $100 \mu \mathrm{m}$ would have a negative effect on the strength of the mortar. The relationship of harmful pore content in the sample was P1 > D0, P2 > D0. The addition of PVA increased the proportion of harmful holes in the mortar, and the compressive strength of the mortar was lower than D0. With the growth of curing age, the total porosity of each sample decreases, while the compressive strength of mortar increases. 


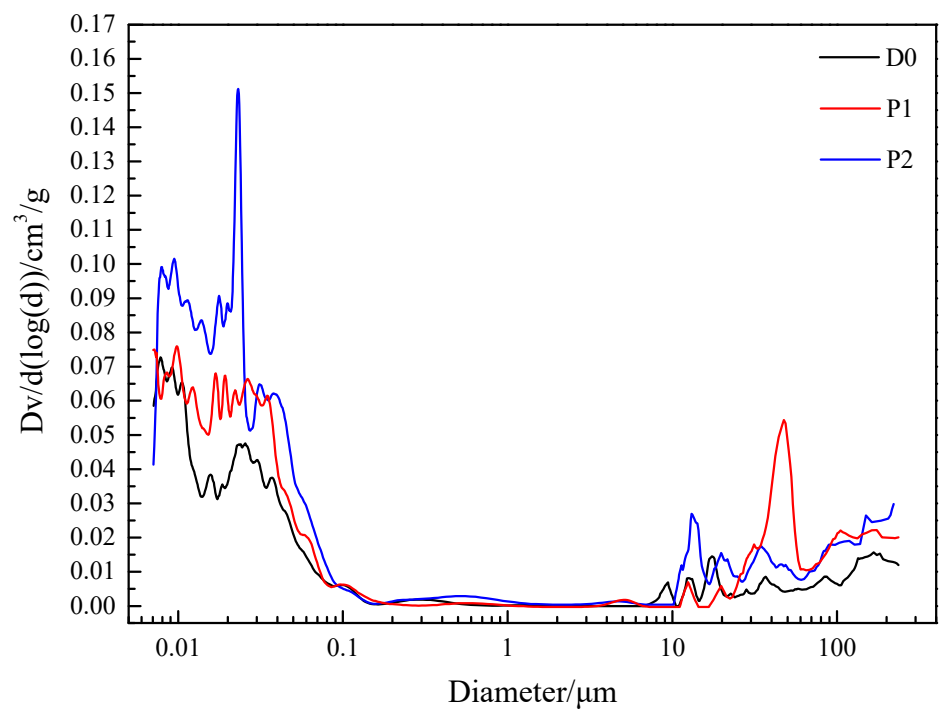

(a)

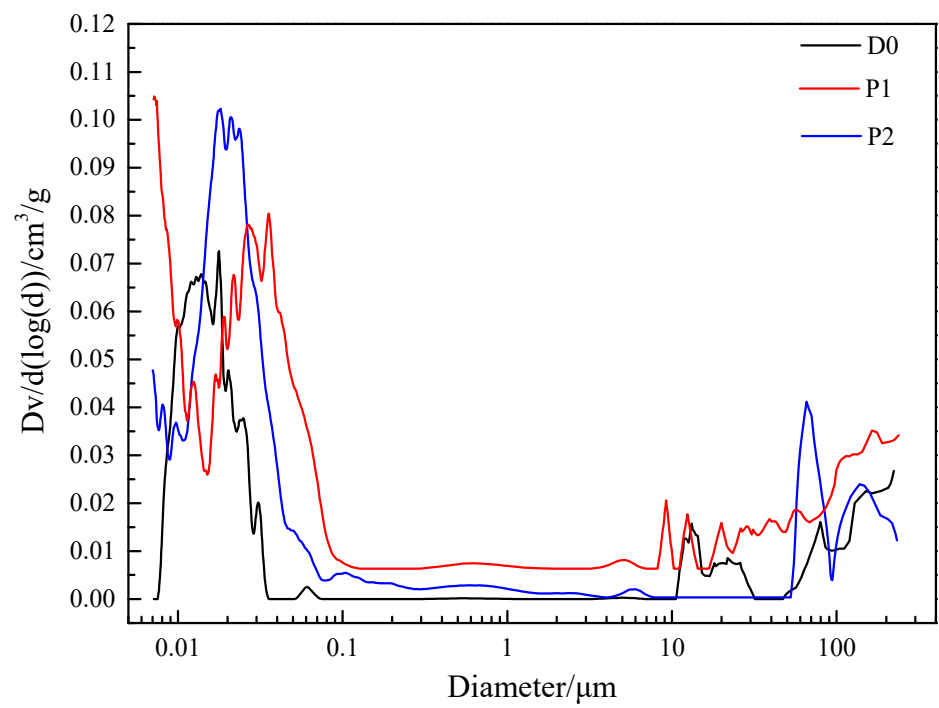

(b)

Figure 13. Pore distribution of composite cement by MIP. (a) Pore distribution of composite cement by MIP at $4 \mathrm{~h}$; (b) pore distribution of composite cement by MIP at 28 days.

(3) SEM Analysis:

The microstructure of D0 and P2 are shown in Figure 14a,b, respectively. As shown in Figure 14a,b, the two groups of samples were closely stacked, the needle and the CSH gel were interwoven - they provide the strength for the cement. However, in Figure 14b, the membrane structure of the polymer was not found, because the hydration products and the polymer films formed a staggered spatial structure. The microstructure of D0 and P2 are shown in Figure 15a,b, respectively, after corrosion by hydrochloric acid. As shown in Figure 15a, AFt was distributed everywhere and the density of structure was decreased. In Figure 15b, the addition of PVA greatly changed the microstructure of the cement. AFt closely grew together and, after the corrosion of hydrochloric acid, the surface was uneven, which was greatly different from Figure 15a. 


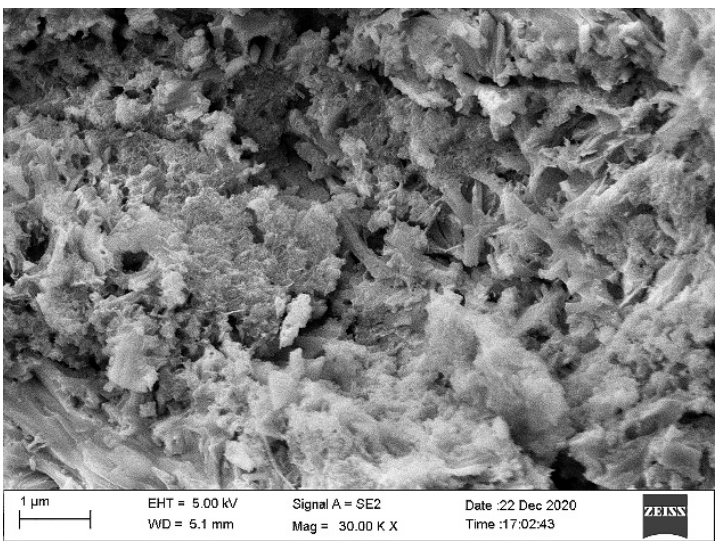

(a)

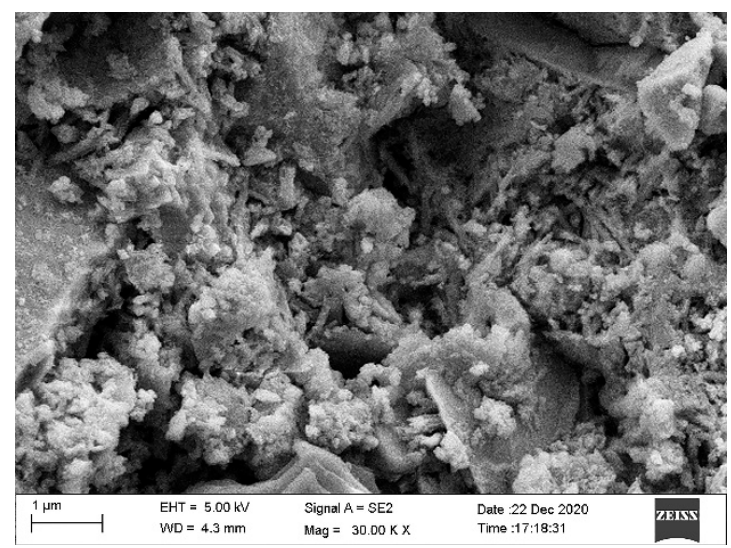

(b)

Figure 14. Before corrosion with hydrochloric acid. (a) D0 before corrosion with hydrochloric acid; (b) P2 before corrosion with hydrochloric acid.

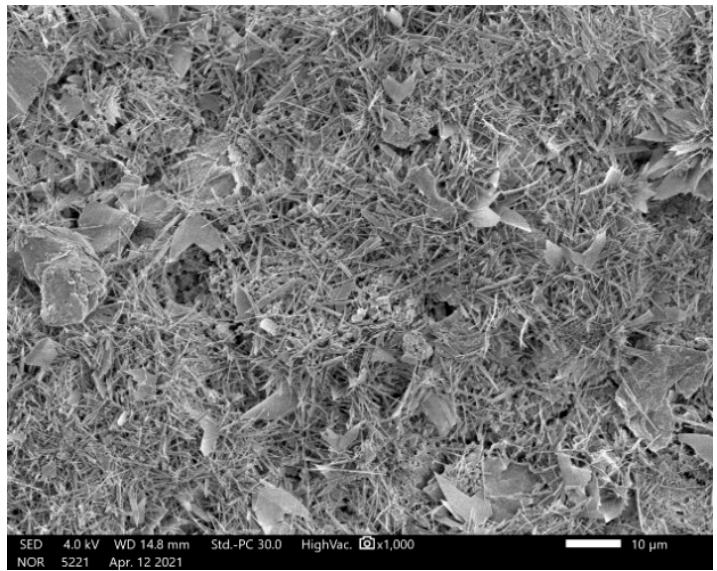

(a)

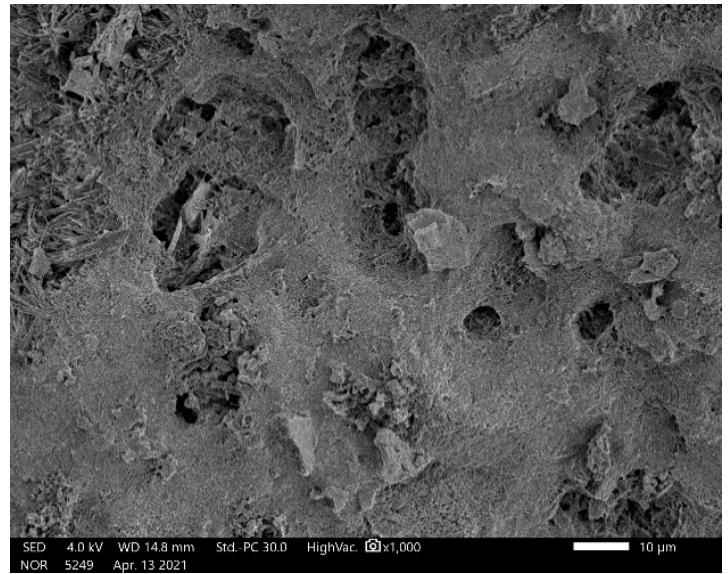

(b)

Figure 15. After corrosion with hydrochloric acid. (a) D0 after corrosion with hydrochloric acid; (b) P2 after corrosion with hydrochloric acid.

\subsection{Discussion}

According to the research results, the addition of PVA could effectively improve the flexural resistance of mortar. At 90 days, $2 \%$ PVA content increased the flexural strength of mortar by $31.7 \%$, and this improvement effect was the most significant. However, PVA had the opposite effect on the compressive properties of mortar. Therefore, the flexural compression ratio of mortar at any age was increased with the increase in PVA. The flexural compression ratio could represent the toughness of mortar to some extent [29-31], while the impact resistance of mortar could better reflect the toughness of mortar. The impact strength of mortar was increased with the increase in PVA. At 1d, the impact strength of mortar with $2 \%$ PVA content was 2.7 times that of the group without PVA. At 28 days, the impact strength of mortar with $2 \%$ PVA content was 1.7 times that of the group without PVA, which shows a very significant improvement effect. Due to the physical action of PVA, the toughness of mortar was improved. In physics, the amount of PVA in mortar internal filtration film, wrapped with cement particles, and the hydration products, form the mutual crisscross in the three-dimensional mesh structure $[14,24,25]$. The toughness of the polymer was much higher than the cement material, thus enhancing the toughness of the mortar.

According to the change in the TG-DSC curve to calculate the amount of ettringite at $4 \mathrm{~h}$ and 28 days, as shown in Table 3 , there were no significant differences among the 
total ettringite. The generation of the ettringite was not affected by PVA, so presumably the volume expansion value caused by ettringite was nearly equal, and PVA mixed and greatly reduced the volume of mortar autogenous shrinkage, especially P1; its autogenous shrinkage was reduced by 4.8 times than D0. Through the calculation of MIP data, the total porosity and pore size distribution data of cement were obtained, as shown in Table 4 . The thickening of PVA and air suction effect increased the gas content of mortar and made it difficult for bubbles to overflow, so finally improved the total porosity of mortar. Of course, the increase in harmful pores had a negative effect on the strength of the mortar, but the increase in total porosity also absorbed a part of the shrinkage stress of mortar [39,40] and reduced the volume shrinkage of mortar. As shown in Figure 7, the PVA of cement particles parcel role effectively delayed the mortar early hydration reaction. After the initial setting, the hydration heat release rate of the group without PVA increased rapidly, while the peak time was nearly the same as the other experimental groups, but the heat release rate was greater than the other experimental groups, which also led to the rapid shrinkage.

Table 4. The porosity and pore size distribution of cement.

\begin{tabular}{ccccccc}
\hline \multirow{2}{*}{ Age } & Sample & \multirow{2}{*}{$\begin{array}{c}\text { Total } \\
\text { Porosity/\% }\end{array}$} & \multicolumn{4}{c}{ Capillary Porosity/\% } \\
\cline { 4 - 7 } & & & $\mathbf{> 1 0 0} \boldsymbol{\mu \mathbf { m }}$ & $\mathbf{5 0 - 1 0 0} \boldsymbol{\mu \mathbf { m }}$ & $\mathbf{1 0 - 5 0} \boldsymbol{\mu m}$ & $<\mathbf{1 0} \boldsymbol{\mu m}$ \\
\hline \multirow{3}{*}{$4 \mathrm{~h}$} & $\mathrm{D} 0$ & 10.95 & 0.97 & 0.37 & 0.75 & 8.86 \\
& $\mathrm{P} 1$ & 15.80 & 1.72 & 1.03 & 1.81 & 11.24 \\
& $\mathrm{P} 2$ & 18.55 & 1.53 & 0.61 & 1.66 & 14.75 \\
\hline \multirow{3}{*}{$28 \mathrm{~d}$} & $\mathrm{D} 0$ & 9.02 & 1.35 & 0.45 & 0.77 & 6.45 \\
& P1 & 13.19 & 1.92 & 0.62 & 1.36 & 9.29 \\
& P2 & 13.77 & 1.60 & 1.34 & 0 & 10.83 \\
\hline
\end{tabular}

\section{Conclusions}

(1) At 90 days, the flexural strength of mortar with 2\% PVA content was $15.4 \mathrm{MPa}$, which was increased by $31.7 \%$, compared with that without PVA;

(2) PVA powder can significantly improve the toughness of mortar. At 90 days, the flexural compression ratio of mortar with $2 \%$ PVA content was 0.166 , which was 1.5 times that of the group without PVA. In Figure 6, the impact strength of mortar with 2\% PVA content at 28 days was $1.72 \mathrm{~J} / \mathrm{cm}^{2}$, which was 1.75 times that of the group without PVA. The modification of cement by PVA was only by physical, without a chemical reaction;

(3) PVA can significantly reduce the volume shrinkage of mortar. The self-shrinkage of mortar with $1 \%$ PVA content was $700 \mu \mathrm{m} \cdot \mathrm{m}^{-1}$, which was 4.8 times lower than the group without PVA.

Author Contributions: Conceptualization, L.M.; tests and data interpretation, Y.H., Z.M., F.H. and Z.H.; writing —original draft preparation, Y.H.; review and editing, Y.H. and L.M. All authors have read and agreed to the published version of the manuscript.

Funding: This research was funded by the National Nature Science Foundation of China (No. 51878346).

Institutional Review Board Statement: Not applicable.

Informed Consent Statement: Not applicable.

Data Availability Statement: The data that supports the findings in this study are available from the corresponding author upon reasonable request.

Acknowledgments: The authors would like to acknowledge the assistance from Peng Liu, Jingkui Zhong, Jun Zhu and Jun Wang from Nanjing Tech University.

Conflicts of Interest: The authors declare no conflict of interest. 


\section{References}

1. Marzouki, A.; Lecomte, A. Properties of Concrete Mixed with Portland-Limestone Cement of Different Grinding Qualities. J. Mater. Civ. Eng. 2016, 29, 1-9. [CrossRef]

2. Jie, Q. Research on Mechanism of Action and Applied Technology of Super Early Strength Repairing Material. Master's Thesis, Chang'an University, Chang'an, China, 2011.

3. Qiao, F.; Chau, C.K.; Li, Z. Property evaluation of magnesium phosphate cement mortar as patch repair material. Constr. Build. Mater. 2010, 24, 695-700. [CrossRef]

4. Lahalle, H.; Patapy, C.; Glid, M.; Renaudin, G.; Cyr, M. Microstructural evolution/durability of magnesium phosphate cement paste over time in neutral and basic environments. Cem. Concr. Res. 2019, 122, 42-58. [CrossRef]

5. Yuan, G. Study on crack resistance of sulphoaluminate cement and ordinary Portland cement concrete. Concrete 2020, 372, 30-33. [CrossRef]

6. Coumes, C.C.D.; Courtois, S.; Peysson, S.; Ambroise, J.; Pera, J. Calcium sulfoaluminate cement blended with OPC: A potential binder to encapsulate low-level radioactive slurries of complex chemistry. Cem. Concr. Res. 2009, 39, 740-747. [CrossRef]

7. Juenger, M.; Winnefeld, F.; Provis, J.L.; Ideker, J.H. Advances in alternative cementitious binders. Cem. Concr. Res. 2011, 41, 1232-1243. [CrossRef]

8. Jin, Y.; Suhua, M.; Weifeng, L.; Dashun, G.; Guofang, T.; Xiaodong, S. Influence of sulphoaluminate cement on the hydration and performance of Portland cement. Concrete 2016, 4, 86-90. [CrossRef]

9. Le Saoût, G.; Lothenbach, B.; Hori, A.; Higuchi, T.; Winnefeld, F. Hydration of Portland cement with additions of calcium sulfoaluminates. Cem. Concr. Res. 2013, 43, 81-94. [CrossRef]

10. Suping, C. Investigation on the Silicate-Sulphoaluminate Compound System Cement. Ph.D. Thesis, Beijing University of Technology, Beijing, China, 2005.

11. Chunyan, F. Preparation and Properties of Portland Cement-Sulphoaluminate Cement-Gypsum Symstem Polymer Cement Waterproof Mortar. Master's Thesis, South China University of Technology, Guangzhou, China, 2012.

12. Baohong, L. The Research on the Materials Used to Repair the Concrete Driveway with Local Flaw. Master's Thesis, Hunan University, Changsha, China, 2005.

13. Yi, L. Study on Polymer Modified Cement-Based Material Used for the Rapid-Repair of the Cement Concrete Pavement. Master's Thesis, Hunan University, Changsha, China, 2014.

14. Ohama, Y. Polymer concrete. Dev. Formul. Reinf. Concr. 2008, 90, 256-269. [CrossRef]

15. Wang, M.; Wang, R.; Yao, H.; Farhan, S.; Zheng, S.; Wang, Z.; Du, C.; Jiang, H. Research on the mechanism of polymer latex modified cement. Constr. Build. Mater. 2016, 111, 710-718. [CrossRef]

16. Frigione, M. 16-Concrete with polymers. Eco-Effic. Concr. 2013, 1, 386-436. [CrossRef]

17. Gemert, D.V.; Czarnecki, L.; Maultzsch, M.; Schorn, H.; Beeldens, A.; Ukowski, P.; Knapen, E. Cement concrete and concretepolymer composites: Two merging worlds. A report from 11th ICPIC Congress in Berlin, 2004. Cem. Concr. Res. 2005, 27, 926-933. [CrossRef]

18. Reches, Y. Nanoparticles as concrete additives: Review and perspectives-ScienceDirect. Constr. Build. Mater. 2018, 175, 483-495. [CrossRef]

19. Ohama, Y. Recent progress in concrete-polymer composites. Adv. Cem. Based Mater. 1997, 5, 31-40. [CrossRef]

20. Toufigh, V.; Hosseinali, M.; Shirkhorshidi, S.M. Experimental study and constitutive modeling of polymer concrete's behavior in compression. Constr. Build. Mater. 2016, 112, 183-190. [CrossRef]

21. Knapen, E.; Gemert, D.V. Polymer film formation in cement mortars modified with water-soluble polymers. Constr. Build. Mater. 2015, 58, 23-28. [CrossRef]

22. Peng, L.; Jianping, Z.; Rong, N.; Huifeng, L. Investigation on the early stage hydration of Portland cement using environment scanning electron microscopy. J. Chin. Ceram. Soc. 2004, 32, 530-536. [CrossRef]

23. Saija, L.M. Waterproofing of portland cement mortars with a specially designed polyacrylic latex. Cem. Concr. Res. 1995, 25, 503-509. [CrossRef]

24. Ohama, Y.; Ramachandran, V.S. Handbook of Polymer-Modified Concrete and Mortars; Noyes Publications: Fukushima, Japan, 1995; pp. 154-196.

25. Grosskurth, K.P.; Konietzko, A. Structure and mechanical behaviour of polymer modified cement concrete. Int. Congr. Polym. Concr. 1987, 5, 171-174.

26. Rashid, K.; Ueda, T.; Zhang, D.; Miyaguchi, K.; Nakai, H. Experimental and analytical investigations on the behavior of interface between concrete and polymer cement mortar under hygrothermal conditions. Constr. Build. Mater. 2015, 94, 414-425. [CrossRef]

27. Ribeiro, M.; Branco, A. Styrene-butadiene polymer action on compressive and tensile strengths of cement mortars. Mater. Struct. 2008, 41, 1263-1273. [CrossRef]

28. Daou, Y.; Assaad, J. Behavior of structural polymer-modified concrete containing recycled aggregates. J. Adhes. Sci. Technol. Int. J. Basic Aspects Adhes. Sci. Its Appl. All Areas Technol. 2017, 31, 874-896. [CrossRef]

29. Ru, W.; Wang, P.M.; Li, X.G. Physical and mechanical properties of styrene-butadiene rubber emulsion modified cement mortars. Cem. Concr. Res. 2005, 35, 900-906. [CrossRef]

30. Wang, R.; Lackner, R.; Wang, P.M. Effect of Styrene-Butadiene Rubber Latex on Mechanical Properties of Cementitious Materials Highlighted by Means of Nanoindentation. Strain 2011, 47, 117-126. [CrossRef] 
31. Ru, W.; Peiming, W.; Yu, P. Comparison of Three Characterization Methods for Flexibility of SBR Latex-Modified Cement Mortar. J. Build. Mater. 2010, 390-394. [CrossRef]

32. Jenni, A.; Zurbriggen, R.; Holzer, L.; Herwegh, M. Changes in microstructures and physical properties of polymer-modified mortars during wet storage. Cem. Concr. Res. 2006, 36, 79-90. [CrossRef]

33. Ma, H.; Tiarr, Y.; Lr, Z. Interactions between Organic and Inorganic Phases in PA- and PU/PA-Modified-Cement-Based Materials. J. Mater. Civ. Eng. 2011, 23, 1412-1421. [CrossRef]

34. Tian, Y.; Jin, X.Y.; Jin, N.G.; Zhao, R.; Li, Z.J.; Ma, H.Y. Research on the microstructure formation of polyacrylate latex modified mortars. Constr. Build. Mater. 2013, 47, 1381-1394. [CrossRef]

35. Xu, L.; Wu, K.; Rößler, C.; Wang, P.; Ludwig, H.M. Influence of curing temperatures on the hydration of calcium aluminate cement/Portland cement/calcium sulfate blends. Cem. Concr. Compos. 2017, 80, 298-306. [CrossRef]

36. $\mathrm{Xu}, \mathrm{L} . ;$ Wang, P.; Zhang, G. Formation of ettringite in Portland cement/calcium aluminate cement/calcium sulfate ternary system hydrates at lower temperatures. Constr. Build. Mater. 2012, 31, 347-352. [CrossRef]

37. Zhang, J.; Li, G.; Ye, W.; Chang, Y.; Song, Z. Effects of ordinary Portland cement on the early properties and hydration of calcium sulfoaluminate cement. Constr. Build. Mater. 2018, 186, 1144-1153. [CrossRef]

38. Qoku, E.; Bier, T.A.; Westphal, T. Phase assemblage in ettringite-forming cement pastes: A X-ray diffraction and thermal analysis characterization. J. Build. Eng. 2017, 12, 37-50. [CrossRef]

39. Lei, W.; Mj, A.; Yw, A.; Yz, D.; St, E. Hydration, shrinkage, pore structure and fractal dimension of silica fume modified low heat Portland cement-based materials. Constr. Build. Mater. 2021, 272, 121-952. [CrossRef]

40. Deboodt, T.; Fu, T.; Ideker, J.H. Evaluation of FLWA and SRAs on autogenous deformation and long-term drying shrinkage of high performance concrete. Constr. Build. Mater. 2016, 119, 53-60. [CrossRef] 